\title{
ALGORITHM OF LOCATION OF WATER INFLUX INTERVALS IN GAS WELLS
}

$$
\text { • • пченко, • • пченко, • • лигм н, • • минов, }
$$

- . ссон, . . ерняк

M. M. Shapchenko, T. A. Shapchenko, S. E. Kligman, L. G. Maminov, O. V. Sasson, V. M. Chernyak

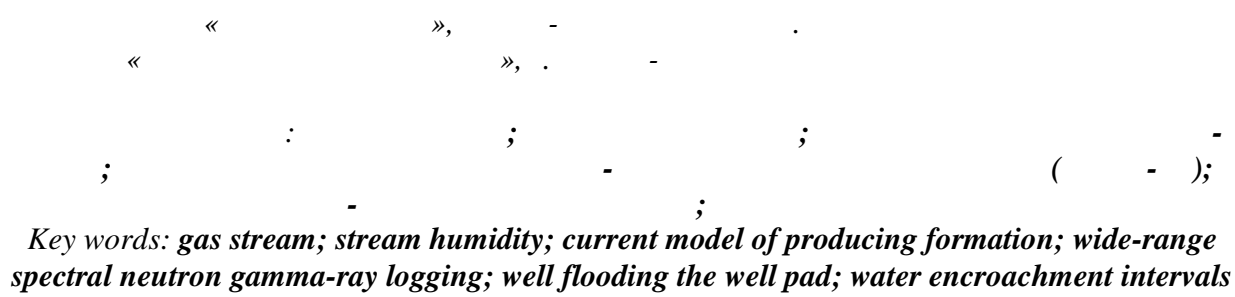

реждевременное обводнение г зовых з лежей н н ч льных эт п х эксплу т ции и в режиме п д ющей добычи нег тивно ск зыв ется н эффективности опер ционной деятельности комп ний-опер торов по добыче. ерьезную проблему предст вляет орг низ ция выявления скв жин-обводнительниц. кв жин обводнительниц - это источник обводнения не только с мой, но и соседних скв жин. ризн ки дополнительной воды проявляются во всех скв жин х куст , поэтому з д ч выявления источник обводнения куст очень сложн .

уществующие технологии специ льных исследов ний скв жин (через сеп р ционные уст новки в комплексе с геофизическими исследов ниями) з тр тны, р стянуты во времени; отслежив ют ч сть действующего фонд, но, с мое гл вное, м лодостоверны. рямым подтверждением этого является история проведения изоляционных р бот (в течение 20 лет) с неуд чными результ т ми. оэтому н сегодняшний день опер тором по добыче пр ктикуется проведение водоизоляционных р бот в ост новившихся (из-з обводнения) скв жин х. онечным результ том т ких р бот является потеря дебит и зн чительное увеличение з тр т.

ыявление скв жины-обводнительницы и водоприточных интерв лов в ней состоит из трех эт пов.

ервый эт $n$.

ель - выявление группы возможных скв жин-обводнительниц. нструментом выявления скв жин-обводнительниц являются фоновые вл гометрические исследов ния всего действующего фонд .

ризн ки отбор скв жин в эту группу т ковы.

- $\quad$ н чение п ровой ф зы г зового поток, превыш ющее среднее зн чение 3 год, к к минимум в 2 р 3 . ример: по всему действующему фонду среднее прир щение п ровой ф зы 3 год сост вляет 0,2 г/м ${ }^{3}$. лее отбир ются скв жины, имеющие прир щение 0,4 г/м ${ }^{3}$ и более, то есть зн чение п ровой ф зы, не соответствующее текущим термоб рическим условиям или резко отлич ющееся от p ссчит нных зн чений (т бл.). примере (см. т бл.) т ким зн чением п ровой ф зы $\left(1,0\right.$ г/м $\left.{ }^{3}\right)$ отмечен скв. 1 (з мер от 06.08.2012 г.) относительно соседних скв жин и фоновых измерений. лительн я р бот скв жины с т ким зн чением п ровой ф зы приводит к р зрушению скелет породы, созд нию песч ных пробок в стволе скв жины, обводнению г зоотд ющего интерв л , р спростр нению фронт воды в соседние скв жины, в зоны с ном льно низкими пл стовыми д влениями ( ).

- $\quad$ егистриров нные зн чительные уменьшения пок з телей скорости и дебит г зового поток , связ нные с ф ктическим уменьшением зоны отбор, то

№ 6, $2015 \stackrel{\text { еФть и г } 3}{ } 41$ 
есть с н личием дополнительной воды в зоне отбор , котор я блокирует под чу г $з$ к перфор ционным отверстиям.

- личие в отобр нной пробе к пельной жидкости смеш нного тип с содерж нием пл стовой и конденс ционной.

ониторинг вл гометрических исследов ний г зового поток

в эксплу т ционных скв жин х

\begin{tabular}{|c|c|c|c|c|c|}
\hline \multirow[b]{2}{*}{ KB } & \multirow{2}{*}{ уст } & \multicolumn{2}{|c|}{06.08 .2012} & \multicolumn{2}{|c|}{17.09 .2012} \\
\hline & & Q г $3, \mathrm{~T} \mathrm{~m}^{3} /$ сут & $\mathrm{W}_{\Gamma}, \Gamma / \mathrm{m}^{3}$ & Q г $3, \mathrm{~T} \mathrm{M}^{3} /$ сут & $\mathrm{W}_{\Gamma}, \Gamma / \mathrm{M}^{3}$ \\
\hline 1 & & 346 & 1,0 & 393,6 & 0,5 \\
\hline 2 & & 421 & 0,5 & 256,8 & 0,4 \\
\hline 3 & & 335 & 0,5 & 348,0 & 0,5 \\
\hline 4 & & 344 & 0,5 & 346,8 & 0,5 \\
\hline
\end{tabular}

скв. куст «» появились призн ки обводнения - зн чение п ровой ф зы в

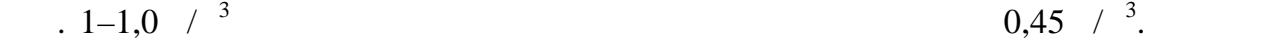
пл новых изменений депрессий, в сторону уменьшения, в шлейфе куст «», зн чение п ровой ф зы в скв жин х куст ср зу уменьшилось до $0,4-0,5 \mathrm{r}_{\mathrm{M}}^{3}$. блюд тельн я скв. 2 резко уменьшил дебит, что ясно пок зыв ет н источник обводнения куст - скв. 2. кв жиной-обводнительницей явил сь скв жин 2.

лгоритмический критерий н личия или отсутствия дополнительной воды (р счетное зн чение п ровой ф зы, соответствующее термоб рическим условиям) p ссчитыв ется по формуле юк чек [1]:

$$
\mathrm{W}_{0,6}=/+
$$

где $\mathrm{W}_{0,6}-\mathrm{p}$ счетное зн чение п ровой ф зы $\left(г / \mathrm{M}^{3}\right)$ при плотности г $30,6 \mathrm{kг} / \mathrm{M}^{3}$, - коэффициент, р вный содерж нию иде льного г 3 ; - д вление, м ;

— попр вк н неиде льность природного г 3 .

зменение п ровой ф зы, несоответствующее термоб рическим условиям, д ет возможность выявления или н личия дополнительной воды в зоне отбор . личие дополнительной воды оценив ется $\mathrm{p}$ зницей $\mathrm{p}$ счетной и измеренной п ровой ф зы.

торой эт $n$.

ель - выявление скв жин-обводнительниц из выбр нной группы первого эт п н основе изменения зн чения п ровой ф зы, скорости и дебит при изменении «н грузки» (пл новых изменений депрессии) н скв жину, результ том которой является появление воды с д влением. этом эт пе исследуются только скв жины, являющиеся источником обводнения. ри необходимости в отдельных скв жин х проводится мониторинг измерений через временные промежутки, не превыш ющие 1 месяц. мея 1-3 мониторинг н блюдений, получ ем ск лярные и векторные величины изменившихся зн чений.

первом и втором эт п х предл г ем я систем н блюдений охв тыв ет весь действующий фонд и ре гирует н все изменения (кв рт льные или месячные изменения депрессии для удерж ния пл нового уровня дебит ), происходящие в скв жин х. егистрируются не позднее 20-30 минут (с момент произошедших изменений) появлением соответствующих г зовых п чек н устье.

истем н блюдений включ ет следующие пок з тели:

-

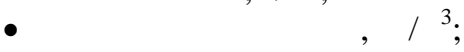

- минер лиз ция, тип воды, г/л, \%;

- скорость поток г з, м/сек;

- м сс поток г $3, \mathrm{~m}^{3}$.

ти п р метры носят оценочный х р ктер и не могут н зыв ться измерительными. 
ценку к честв г зового поток (вл госодерж ние поток г з эксплу т ционной скв жины н предмет н личия воды в $\mathrm{p}$ зных ф зовых состояниях: п ровой ф зы и к пельной ф зы) проводят через пробоотборники при помощи индик торных методов.

нструменты оценки:

- термогигрометр -6 (п ров я ф 3 );

- «к плеотбойник» $\quad-4$ (к пельн я ф з ); цель - определение минер лиз ции и тип к пельной воды, выносимой г зовым потоком н устье скв жины.

ценк содерж ния текущего зн чения п ровой ф зы, несущей в себе информ цию о н личии п ров воды, в зоне отбор и н устье, в отобр нной пробе г 3 , производится термогигрометром -6. ри этом получ ем зн чение п ровой $ф$ зы, близкое к достоверному.

ров я ф з несет информ цию о н личии воды в пл стовых термоб рических условиях. то устойчив я форм физического состояния воды. поверхности производят осушку г з от п ровой ф зы с помощью химии, д влений и темпер тур (н очистных сооружениях ), т к к к применение сеп р ционных уст новок, с целью отделения п ровой ф зы не эффективно. то говорит о ее устойчивости к мех ническим воздействиям.

ce неустойчивые состояния воды в результ те переп д д влений $(\Delta=$ пл - 3 б.) выносятся из скв жины г зовым потоком в виде к пли, которую мы отбир ем н поверхности -4 для определения минер лиз ции и тип воды, которые определяются н уровне оценки.

ин мические х р ктеристики (скорость, дебит) г зового поток оценив ются ультр звуковым р сходомером г 3 RG-601, предн зн ченным для измерения объемного (м ссового) р сход жидкостей и г зов, протек ющих по трубопроводу.

редл г ем я систем н блюдений проводится без ост новки скв жин, экономичн, экологически безоп сн, д ет информ цию 3 короткий срок. текущий момент является н иболее достоверной из всех видов промысловых исследов ний. роцесс регистр ции происходит в один ковых условиях тем же комплектом оборудов ния.

реимуществом предл г емой системы является быстрый охв т действующего фонд , дешевизн и более высок я достоверность.

ретий эт $n$.

иды обводнения в эксплу т ционных г зовых скв жин х:

- пропл стковое обводнение (прорывы пл стовой воды, техногенной жидкости или фильтр тов буровых р створов при бурении н нижележ щие пл сты в зоны по н иболее прониц емым прослоям продуктивного пл ст );

- обводнение в монолитном пл сте (прорывы пл стовой или техногенной жидкости по пл сту);

- подошвенное обводнение (подтягив ние конус воды к интерв лу перфор ции вследствие подъем в процессе эксплу т ции скв жины);

- 3 колонные перетоки воды (поступление чуждой воды по з колонному простр нству в результ те нек чественного р зобщения пл стов или н рушения герметичности цементного кольц в процессе эксплу т ции скв жины);

- негерметичность эксплу т ционной колонны (приток воды в скв жину через н рушения эксплу т ционной колонны);

- межскв жинные перетоки.

г зовых скв жин х месторождений обводнение продукции объектов добычи происходит в результ те сочет ния нескольких видов обводнения. бщим для всех скв жин с обводненной продукцией являются прорывы воды по высокопронии емым интерв $л м$ пл $\mathrm{cm}$, н ходящимся в р зличных ч стях продуктивного р зрез и вне него. оэтому достоверное выявление интерв лов водопритоков р зличного вид лежит в основе эффективности водоизоляционных мероприятий, носит определяющий х р ктер удорож ния или удешевления добычной продукции. сегодняшний день единственным информ ционным инстру-

№ 6,2015 е 
ментом, позволяющим достоверно выявлять в тонкослоистом р зрезе ктивные прослои, н сыщенные сл боминер лизов нной водой, является спектр льный нейтронный г мм -к рот ж широкоди п зонный (

- ).

выявленной скв жине-обводнительнице проводятся ядерные исследов ния прибором - для выделения интерв л обводнения (или нескольких интерв лов) с целью проведения в них геолого-технических мероприятий ( ) по водоизоляционным р бот м ( ).

екущ я ди гностик модели з лежи в скв жине-обводнительнице (водоприточные интерв лы и их ктивность) пок з ны н рисунке.

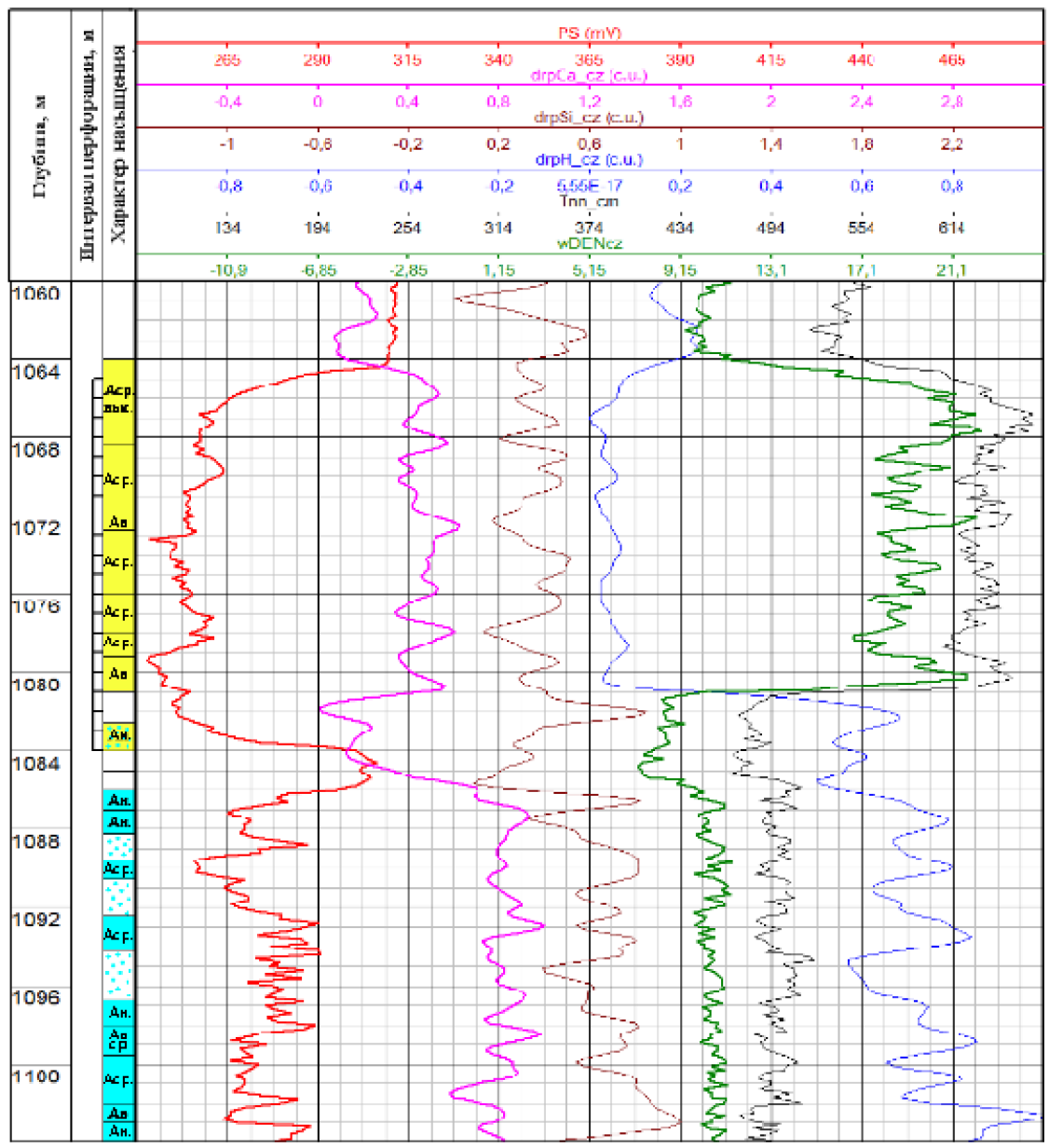

Условные обозначенгя: Ан., Аср., Ав. - активность притока газа (волы): низкая, средняя, высокая

$\square$ - огсугетвие притока

Характер насыщентя:

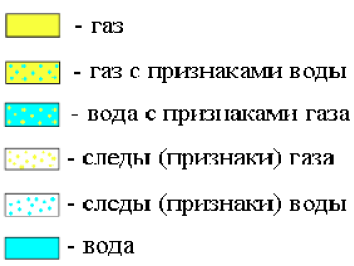

Рисунок. Текущцая диагностика модели залежи скважины-обводнительницы СНГК-Ш

бот прибор - основ н н облучении горных пород потоком нейтронов от мпульного источник и регистр ции плотности поток тепловых ней- 
тронов н двух и более р сстояниях от источник излучения. - включ ет, помимо спектрометрии, интегр льные методы , , , - . ся информ ция извлек ется из спектр - . дновременн я регистр ция функций водородосодерж ния, объемной плотности, времени жизни, соотношения п р метров p ссеяния и поглощения тепловых нейтронов з один спуск исключ ет неоднозн чность интерпрет ции. олуч емые многометодные д нные не требуют пп p турной, простр нственной и временной привязки. - позволяет получить д нные, н логичные двухзондовым интегр льным - , позволяет оценить нейтронные и г мм -лучевые п р метры исследуемых сред и их соотношение. сследов ния проводятся через и лубрик тор в режим х «дин мики» и «ст тики». рибор - дополнительно осн щен высокочувствительным термометром. рибор предст вляет собой трехзондовое устройство. сследуется 3 зоны в р ди льном н пр влении: перв я зон - 30 см, втор я зон $-50 \mathrm{~cm}$, третья зон - $80 \mathrm{~cm}$. нформ ция весьм в жн для решения з д ч определения текущего н сыщения коллекторов, литологии тонкослоистого р зрез, прочностных и фильтр ционно-емкостных свойств пород, ктивных водон сыщенных интерв лов и трещинов тых зон в условиях обводнения скв жин сл боминер лизов нной водой. к производится текущ я ди гностик объект добычи. условиях сложного обводнения достоверн я текущ я модель объект добычи необходим для определения интерв л и способ проведения водоизоляционных $\mathrm{p}$ бот.

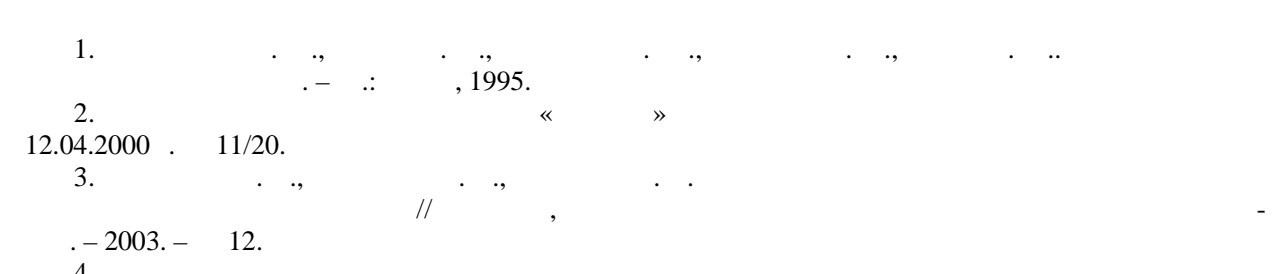
вых скв жин // еология, геофизик и р зр ботк нефтяных и г зовых месторождений. - 2005. - № 1

5. пособ экспрессного определения вл жности продукции г зовых скв жин: п тент н изобретение № 2255218, 2005.

6. сильев . ., пченко . . . л гометрия (водность) - комплексный пок з тель, х р ктеризующий процесс $\mathrm{p}$ зр ботки г зовой з лежи н текущий момент // еология, геофизик и р зр ботк нефтяных и г зовых месторождений. - 2007. - № 7.

7. ндреев . ., хмедс фин . ., ирс нов . ., езм терных . ., ривицкий . ., инченко . . омплекс новых методов контроля р зр ботки г зовых и г зоконденс тных месторождений (минимиз ция технического воздействия н окруж ющую среду). - б: ук , 2010.- .47-86.

8. пченко . ., пченко . ., отов . ., утфуллин . ., гомедов . ., ургузов . ., оробьев . ., едведев . . кспресс метод мониторинговых исследов ний для оценки дин мических х р ктеристик объектов добычи г зовых и г зоконденс тных з лежей (вл гометрия, оценк скорости и м ссы поток г з ) // втом тиз ция, телемех низ ция и связь в нефтяной промышленности. -2013 . - № 7.

9. пченко . ., пченко . ., орофеев . ., оробьев . ., опнев . ., убницкий . . ош говое регулиров ние добычи г з с целью оптимиз ции технологического режим добыв ющих скв жин сеном нских з лежей // ефтепромысловое дело. - 2014. - № 11. - . 16-19.

10. ременные методические рекоменд ции по проведению и интерпрет ции д нных спектрометрического г мм -к рот ж « »-г. ктябрьский, 2002.

11. урб тов . ., пченко . ., орисов . ., орозняк . ., ирс нов . ., йко . . пп р турно-методический комплекс широкоди п зонного спектр льного нейтронного г мм к рот ж ( - ) и пр ктические результ ты его применения в условиях $\mathrm{p}$ йнего евер п дной ибири // еология, геофизик и р зр ботк нефтяных и г зовых месторождений. ефтепромысловое дело. - 2014. - № 6.

12. трог нов . ., огульский . ., х нь, трог нов . ., зр ботк технологии изоляции водопритоков и водоперетоков в скв жин х н месторождениях // борник н учных трудов по результ т м 32000 г. 32001.

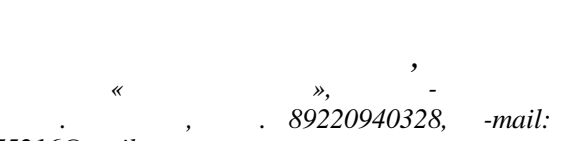

Information about the authors

Shapchenko M. M. Director of LLC NPF «Urengoyspecservice», Yamalo-Nenetski Autonomous Okrug, phone: 89220940328, e-mail: 08475216@mail.ru 
пиенко тьян лекс ндровн, гл вный геолог, " ренгойспецгис», $м$ лоенецкий . пгт. ренгой, тел. 8(34534)9349, e-mail:08475216@mail.ru.

минов ев еоргиевич, директор

" 3 род кшн нжиниринг», 2. етербург, тел. 89219306270 , e-mail: пеп rud@mail.ru

$$
\text { лигм н ергей рикович, инженер }
$$

« $з$ род кшн нжиниринг», 2. нкт етербург, тел. 89219674248, e-mail: kgsrus@gmail.com

$$
\text { ссон льг икторовн, инженер }
$$

" 3 род кшн нжиниринг», нкт- етербург, meл. 89219417034, e-mail: o.mescherina@ya hoo.co.com

$$
\text { ерняк лерий ркович, инженер, }
$$

" 3 родкин нжиниринг», нкт- етербург, meл.89219697300,e-mail: leader@katod.ru
Shapchenko T. A., chief geologist of LLC NPF "Urengoyspecservice», Yamalo-Nenetski Autonomous Okrug, phone: 8(34534)93497, e-mail: 08475216@mail.ru.

Maminov L. G., Director of LLC «GasProductionEngineering», St. Petersburg, phone: 89219306270, e-mail:nemerud@mail.ru

Kligman S. E., engineer of LLC «GasProductionEngineering», St. Petersburg, phone: 89219674248 , e-mail:kgsrus@gmail.com

Sasson $\boldsymbol{O} . \boldsymbol{V}$., engineer of LLC «GasProduction Engineering», St. Petersburg, phone: 89219417034, e-mail: o.mescherina@yahoo.co.com

Chernyak V. M., engineer of $L L C$ «GasProductionEngineering», St. Petersburg, phone: 89219697300,e-mail: leader@katod.ru 